\title{
Hygroscopic growth and activation of HULIS particles: experimental data and a new iterative parameterization scheme for complex aerosol particles
}

\author{
M. Ziese ${ }^{1}$, H. Wex ${ }^{1}$, E. Nilsson ${ }^{2}$, I. Salma ${ }^{3}$, R. Ocskay ${ }^{3}$, T. Hennig ${ }^{1}$, A. Massling ${ }^{1}$, and F. Stratmann ${ }^{1}$ \\ ${ }^{1}$ Leibniz-Institute for Tropospheric Research, Permoser Strasse 15, 04318 Leipzig, Germany \\ ${ }^{2}$ Lund University, Department of Nuclear Physic, P.O. Box 118, 22100 Lund, Sweden \\ ${ }^{3}$ Eötvös University, Institute of Chemistry, P.O. Box 32, 1518 Budapest, Hungary
}

Received: 3 August 2007 - Published in Atmos. Chem. Phys. Discuss.: 21 September 2007

Revised: 13 February 2008 - Accepted: 2 March 2008 - Published: 28 March 2008

\begin{abstract}
The hygroscopic growth and activation of two HULIS (HUmic LIke Substance) and one Aerosol-WaterExtract sample, prepared from urban-type aerosol, were investigated. All samples were extracted from filters, redissolved in water and atomized for the investigations presented here. The hygroscopic growth measurements were done using LACIS (Leipzig Aerosol Cloud Interaction Simulator) together with a HH-TDMA (High Humidity Tandem Differential Mobility Analyzer). Hygroscopic growth was determined for relative humidities (RHs) up to $99.75 \%$. The critical diameters for activation were measured for supersaturations between 0.2 and $1 \%$. All three samples showed a similar hygroscopic growth behavior, and the two HULIS samples also were similar in their activation behavior, while the Aerosol-Water-Extract turned out to be more CCN active than the HULIS samples. The experimental data was used to derive parameterizations for the hygroscopic growth and activation of HULIS particles. The concept of $\rho_{\text {ion }}$ (Wex et al., 2007a) and the Szyszkowski-equation (Szyszkowski, 1908; Facchini et al., 1999) were used for parameterizing the Raoult and the Kelvin (surface tension) terms of the Köhler equation, respectively. This concept proved to be very successful for the HULIS samples in the saturation range from RHs larger than $98 \%$ up to activation. It was also shown to work well with data on HULIS taken from literature. Here, different atmospheric life-times and/or different sources for the different samples showed up in different coefficients for the parameterization. However, the parameterization did not work out well for the Aerosol-Water-Extract.
\end{abstract}

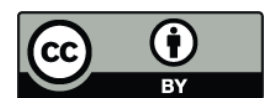

Correspondence to: $\mathrm{H}$. Wex (wex@tropos.de)

\section{Introduction}

One important topic in current atmospheric research is to quantify the indirect aerosol effect and here especially how aerosol particles (natural and/or anthropogenic) may influence important cloud properties like cloud albedo (Twomey, 1974) or lifetime (Albrecht, 1989). For quantification of the indirect effect, the hygroscopic growth and activation behavior of atmospheric aerosol particles has to be known. In former studies this was investigated for inorganic substances like sodium chloride $(\mathrm{NaCl})$ or ammonium sulfate $\left(\left(\mathrm{NH}_{4}\right)_{2} \mathrm{SO}_{4}\right)$ (Rader and McMurry, 1986; Tang and Munkelwitz, 1994; Tang, 1996; Lance et al., 2006). Also organic substances, e.g. dicarboxylic acids and sugars, and simple mixtures were used in earlier investigations (Bilde and Svenningsson, 2004; Broekhuizen et al., 2004; Henning et al., 2005; Wex et al., 2007b). Recently, humic-like substances (HULIS) have gained attention in cloud research. HULIS are composed of polymeric organic molecules with a large number of functional groups. The exact chemical composition of HULIS, which may depend on the actual source process and on atmospheric aging processes, is unknown. The concentration of HULIS in urban background varies between 0.3 and $1.6 \mu \mathrm{g} / \mathrm{cm}^{3}$ (Samburova et al., 2005). Kiss et al. (2005) stated that HULIS might contribute up to $60 \%$ of the organic mass of fine atmospheric aerosol particles, while Salma et al. (2006) found that it makes up to $54 \%$ of the water-soluble organic carbon (WSOC). In investigations regarding the hygroscopic growth of HULIS particles, growth factors between 1.08 and 1.47 (depending on the source) were reported at a relative humidity $(\mathrm{RH})$ of $90 \%$ (Dinar et al., 2007; Gysel et al., 2004). Also the activation of HULIS particles to cloud droplets has been the topic of recent

Published by Copernicus Publications on behalf of the European Geosciences Union. 
research activities (Dinar et al., 2006b; Wex et al., 2007a; Asa-Awuku et al., 2008).

One problem in dealing with HULIS is the existing spread regarding its material properties. The density of HULIS is reported to be between $1.4 \mathrm{~g} / \mathrm{cm}^{3}$ and $1.72 \mathrm{~g} / \mathrm{cm}^{3}$ (AsaAwuku et al., 2008; Dinar et al., 2006a; Gysel et al., 2004). Published values for the molecular weight vary between $410 \mathrm{~g} / \mathrm{mol}$ and $780 \mathrm{~g} / \mathrm{mol}$ (Dinar et al., 2006b; Asa-Awuku et al., 2008; Samburova et al., 2005). Furthermore, HULIS lowers the surface tension of the solution droplets. Kiss et al. (2005), Salma et al. (2006), Dinar et al. (2006b), and Taraniuk et al. (2007) reported reductions in surface tension by $25 \%$ to $45 \%$ compared to the surface tension of water, with the measured surface tensions depending on the concentration and the age of the solution (Salma et al., 2006; and Taraniuk et al., 2007).

The reasons for the spread of reported HULIS properties originates in a possibly wide range of different molecules that are generally included in HULIS (Graber and Rudich, 2006), in different generation mechanisms in the atmosphere, and also in a change of the properties of HULIS in the atmosphere due to aging. The latter two points can be seen in the study by Dinar et al. (2006b), where HULIS from fresh biomass burning aerosol and from the same, but aged, aerosol were compared and were found to differ.

Despite past efforts, no consistent picture exists regarding the connection between hygroscopic growth and activation of HULIS particles, as it also is the case for other organic species (Kanakidou et al., 2005, McFiggans et al., 2006). In the case of HULIS, the surface tension that was needed to achieve a consistent description from hygroscopically grown to activated particles differed in different studies (Dinar et al., 2006b; Wex et al., 2007a; Asa-Awuku et al., 2008). Therefore, in this work, we extent the hygroscopic measurements to the RH range larger than $98 \%$, i.e., to the range that has to be considered when examining the possible influences of surface tension on hygroscopic particle growth.

In the following, we describe the investigation of the hygroscopic growth and activation of two HULIS and one Aerosol-Water-Extract sample, all of them taken downtown Budapest, Hungary. The first HULIS sample was sampled in spring 2005, while the second sample for HULIS and the Aerosol-Water-Extract were taken in summer 2006. The Aerosol-Water-Extract was included in the study to compare the influence of pure HULIS on hygroscopic growth and activation with the influence of HULIS mixed with the additional soluble compounds of the atmospheric aerosol, i.e., to detect if effects of HULIS and soluble inorganic matter are solely additive, or if other effects come into play.

All samples were extracted from filters, redissolved in water and atomized for the investigations presented here. The hygroscopic growth measurements were done using LACIS (Leipzig Aerosol Cloud Interaction Simulator) together with a HH-TDMA (High Humidity Tandem Differential Mobility Analyzer). Hygroscopic growth was determined for RHs up to $99.75 \%$. The critical diameters for activation were measured using LACIS for supersaturations of approximately $0.2,0.4,0.6,0.8$ and $1 \%$. A parameterization is developed with which we manage to consistently describe the hygroscopic growth and the activation of the HULIS particles from our samples, with slightly different values for the coefficients of the parameterization for the two samples. We also probe the parameterization with three different atmospheric HULIS samples, using data that had been published in the literature previously (Dinar et al., 2006b and Dinar et al., 2007). Here, the parameterization also describes hygroscopic growth and activation well, with the coefficients covering a wider range, probably due to the larger variability in the different HULIS samples. The parameterization was also used to describe hygroscopic growth and activation of the Aerosol-Water-Extract particles, for which , however, it did not work out well.

\section{Experimental setup and procedure}

For the investigation regarding the hygroscopic growth and activation of HULIS and Aerosol-Water-Extract particles presented here, two different instruments, a) a HH-TDMA (Hennig et al., 2005) and b) LACIS (Stratmann et al., 2004) were used. The HH-TDMA was applied to measure the hygroscopic growth below 98\% RH while LACIS was utilized to investigate the hygroscopic growth between $98 \%$ and 99.75\% RH and to determine the critical diameter for activation at several supersaturations from 0.2 to $1 \%$.

The version of LACIS used for this study consists of a flow tube of $1 \mathrm{~m}$ length. Aerosol and sheath air were humidified (aerosol: MH-110-12S-4, sheath air: PH-30T-24KS, Perma Pure) to well defined dew point temperatures (reproducibility approx. $0.01 \mathrm{~K}$ ) before entering the flow tube. The dew point temperatures and the LACIS wall temperature determine the water vapor saturation or the maximum supersaturation in the flow tube. For the hygroscopic growth measurements described here, LACIS was operated in its sub-saturated mode of operation (Wex et al., 2005). In this mode the wall temperature $\left(20^{\circ} \mathrm{C}\right)$ was above the dew point temperature (between $19.67^{\circ} \mathrm{C}$ and $19.97^{\circ} \mathrm{C}$ ) of the aerosol and the sheath air. The residence time of the particles in the flow tube is two seconds. While passing through the flow tube, particles adjusted to the $\mathrm{RH}$ present in the tube.

The supersaturated mode of operation was applied for the activation measurements (Wex et al., 2006). In contrast to the sub-saturated mode, the wall temperature (here varied between $5.51^{\circ} \mathrm{C}$ and $5.82^{\circ} \mathrm{C}$ ) is below the dewpoint temperature $\left(22.0^{\circ} \mathrm{C}\right)$ of the aerosol and the sheath air. With increasing water vapor saturation (decreasing wall temperature) the maximum saturation reached in LACIS increases. The particles activate in LACIS, if the maximum saturation reached is equal or above their critical supersaturation. 
In LACIS, the particles are exposed to the maximum saturation only for a fraction of a second. As will be described later, both, HULIS and Aerosol-Water-Extract particles, could be activated readily. As the time for the exposure to the maximum saturation is significantly below that of the exposure to a constant RH during the measurements of hygroscopic growth, i.e. the above mentioned residence time of two seconds, we assume that this residence time for hygroscopic growth measurements was sufficient to allow the particles to reach their equilibrium diameter at the RH in the flow tube.

To calibrate the RH and the supersaturation in LACIS for the different temperature set-ups used during the measurements, ammonium sulfate particles of known sizes (selected by a DMA) were used prior to the experiments.

At the LACIS outlet, an optical particle spectrometer measures the size of the grown particles (Kiselev et al., 2005). For the investigations presented here, the spectrometer was calibrated before and after the campaign using PSL particles of 7 different sizes between $203 \mathrm{~nm}$ and $2390 \mathrm{~nm}$ (Duke Scientific) and $\mathrm{SiO}_{2}$ particles with diameters between $490 \mathrm{~nm}$ and $1570 \mathrm{~nm}$ (Duke Scientific), respectively. Results of both calibrations were virtually identical. The refractive index used to retrieve the droplet size from the measured scattered light intensities was 1.65 for HULIS (Hoffer et al., 2006). For the Aerosol-Water-Extract, a value of 1.53 was used, corresponding to the fact that the major water soluble inorganic constituent of the latter was sulfate. When determining the sizes of the hydrated particles, a change of the refractive index with increasing size was taken into account by using a volume mixing rule, as described in Kiselev et al. (2005).

Recently, Dinar et al. (2008) published complex refractive indices for particles generated from different HULIS samples. For the real part of the refractive index they found values between 1.56 and 1.64, depending on sample and wavelength. Using a value of 1.56 instead of 1.65 in the LACIS data evaluation only leads to change in the refractive index for the evaluated particle/droplet sizes (growth factors 1.7 and above, as shown later in this work) below $1.5 \%$. Likewise, had we used 1.65 as refractive index for the AerosolWater-Extract (instead of 1.53), the received hygroscopic growth would have been lowered by less then $10 \mathrm{~nm}$ (less than 3\%). The determined supersaturations would even be less influenced by uncertainties in the refractive index, due to the solution of the hydrated particles/droplets that gets more diluted as the particles grow. So, in general, the influence of an uncertainty in the real part of the refractive index on the LACIS data evaluation is only of minor importance. When introducing a complex part of the refractive index to the LACIS data evaluation, using values as reported by Dinar et al. (2008), deviations from the original evaluation were found to be below $2 \%$ and thus were considered only to be of minor influence, too.

The HH-TDMA used in this study is described in detail in Hennig et al. (2005). The specific feature of this HH-
TDMA is the combination of two highly stable temperature controlled water baths. The first water bath contains the humidification section and the second water bath contains the Differential Mobility Analyzer (DMA) measuring the hydrated particles sizes. In the humidification section the $\mathrm{RH}$ of the aerosol air and sheath air for the DMA are produced separately by mixing dry synthetic air and highly humidified synthetic air. The synthetic air was humidified in a water-togas humidifier ( $\mathrm{PH}$ series, ANSYCO), while the aerosol was humidified in a gas-to-gas humidifier (PD series, ANSYCO). While the water bath for the humidification section was operated at $22.5^{\circ} \mathrm{C}$, the water bath for the DMA was operated at $20^{\circ} \mathrm{C}$. The temperature decrease between the humidification section and the DMA enables measurements at RHs up to $98 \%$ with high accuracy by helping to overcome technical limitations of the used humidifier membranes and the used RH sensors. HH-TDMA measurements of the HULIS samples and of the Aerosol-Water-Extract were performed at RHs between $80 \%$ and $98 \%$. Before and after the measurements, calibration scans were made using ammonium sulfate.

To collect the particle material investigated in this study, two aerosol samples $\left(\mathrm{PM}_{2.5}\right)$ were taken in downtown $\mathrm{Bu}-$ dapest, Hungary, applying a high-volume sampler with Whatman QM-A quartz fiber filters. The filters were heated prior to sampling, to remove possible contaminants. The first sample was taken during spring 2005 in the non-heating season and only HULIS was extracted by means of a modified solid-phase extraction protocol (Varga et al., 2001). Concerning the second sample, which was taken in summer 2006, water extraction of the aerosol sample from the filter was performed in an identical way for two fractions of one filter. This was done to allow the production of two different samples, a pure HULIS sample and a sample that contained all water soluble material (named Aerosol-Water-Extract in the framework of this paper). For this, the quartz filter samples were extracted by high-purity reagent water (Milli-Q) for about $48 \mathrm{~h}$ in two steps. The joint water extract was filtered through a PVDF syringe membrane filter with a pore size of $0.22 \mu \mathrm{m}$ to remove the filter debris and suspended insoluble particles. For the Aerosol-Water-Extract, the solution was freeze-dried immediately after the filtration at a temperature of liquid nitrogen and it was kept frozen during storage and transport. For further details on the extraction scheme for the HULIS samples from the prepared solution, the reader is referred to Salma et al. (2006) and Salma et al. (2007).

For the second HULIS sample, concentration of carbon in HULIS was measured by a Multi N/C 2100 S total carbon analyzer (Analytik Jena, Germany). The mean atmospheric concentrations of HULIS was $4.7 \mu \mathrm{g} / \mathrm{m}^{3}$ using the organic matter-to-organic carbon mass conversion factor of 1.81 derived especially for HULIS (Salma et al., 2007). The Aerosol-Water-Extract sample investigated was prepared from a quarter $(25.4 \%)$ section of the filter. In total, it contained $6.0 \mathrm{mg}$ of HULIS, compared to $2.0 \mathrm{mg}$ of sulfate. The atmospheric concentration of sulfate in the original 


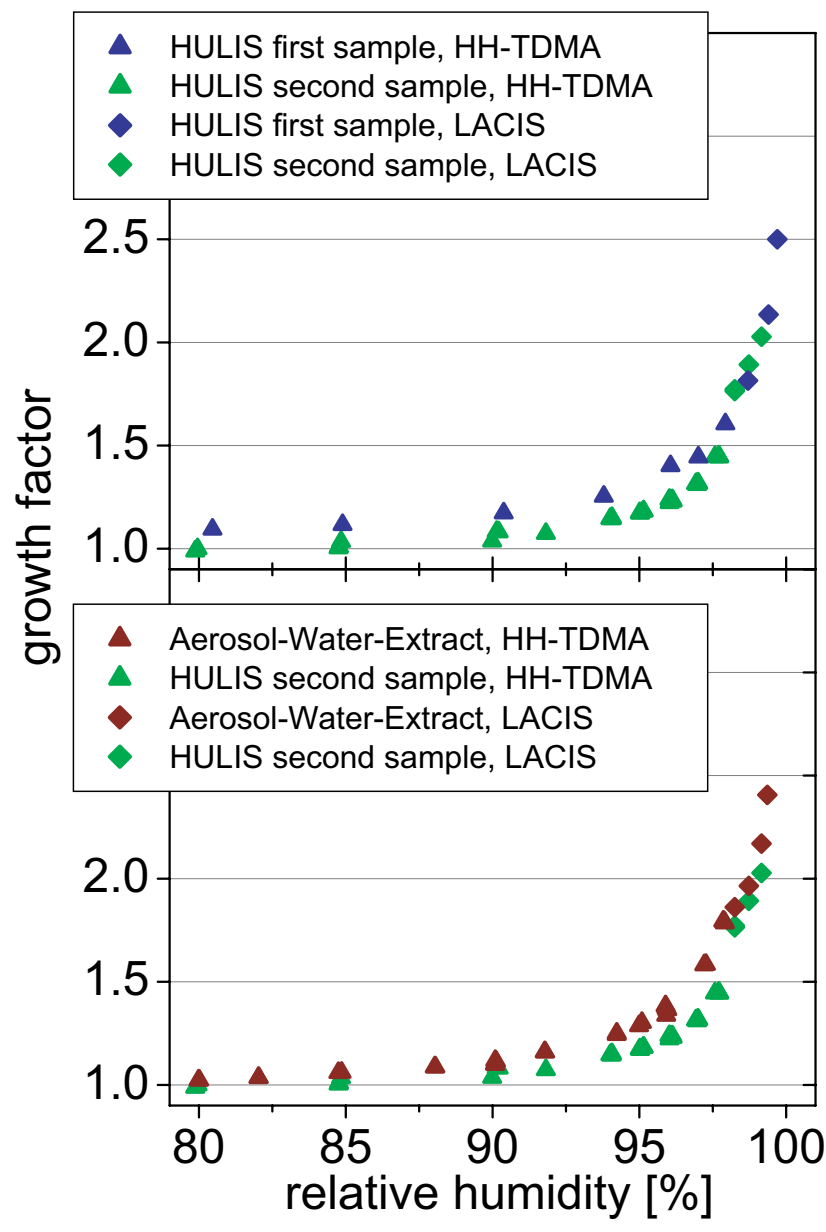

Fig. 1. Hygroscopic growth factors measured with LACIS (diamonds) and the HH-TDMA (triangles) as function of RH for particles from the two HULIS and the Aerosol-Water-Extract samples. The different dry sizes used in the different measurements are given in the text.

sample was determined to be $1.7 \mu \mathrm{g} / \mathrm{cm}^{3}$.

To generate the HULIS and Aerosol-Water-Extract particles investigated, the extracted samples were dissolved in double de-ionized Milli-Q water with an additional reduction of total organic carbon (TOC) $(18.2 \mathrm{MOhm}, \mathrm{TOC}<4 \mathrm{ppb})$. The solution was atomized by means of an atomizer (type TSI 3075). The generated solution droplets were dried (below $13 \% \mathrm{RH}$ ) utilizing a diffusion dryer. A dry particle size was selected by means of a DMA (Differential Mobility Analyzer, type Vienna Medium). Finally, the size selected particles were supplied to the HH-TDMA and LACIS. For the hygroscopic growth measurements, dry particle diameters of $200 \mathrm{~nm}$ for the first and $230 \mathrm{~nm}$ for the second HULIS sample were selected for the LACIS measurements, while $165 \mathrm{~nm}$ was used for the LACIS measurements of the Aerosol-WaterExtract. For the HH-TDMA measurements, dry diameters of $100 \mathrm{~nm}$ for the first HULIS sample and $100 \mathrm{~nm}$ and $230 \mathrm{~nm}$ for the second HULIS sample were used, while $100 \mathrm{~nm}$ particles were selected for the Aerosol-Water-Extract. To study the activation behavior of both HULIS and Aerosol-WaterExtract particles, the dry diameter of the particles was varied between 25 and $200 \mathrm{~nm}$.

\section{Measurement results}

In this section the results of the measurements regarding the hygroscopic growth and activation behavior of the investigated HULIS and the Aerosol-Water-Extract samples are presented and discussed.

\subsection{Hygroscopic growth}

Figure 1 depicts the results of the hygroscopic growth measurements. Given are the measured growth factors (corresponding to the ratio of wet to dry particle diameters, $\left.d_{p} / d_{p, 0}\right)$ as function of RH. Here the results of LACIS (diamonds) and HH-TDMA measurements (triangles) are shown. As to be seen, the growth factors of both HULIS samples are comparable, although the hygroscopic growth of the first sample exceeds that of the second sample slightly (Fig. 1, upper panel). For the second HULIS sample, hygroscopic growth factors derived with the HH-TDMA at dry sizes of $100 \mathrm{~nm}$ and $230 \mathrm{~nm}$ agree within measurement uncertainty, i.e. a small difference that would originate in the Kelvin effect was not clearly resolved by our measurements. Particles generated from the Aerosol-Water-Extract exhibit slightly larger growth factors compared to the corresponding HULIS particles from the second sample (Fig. 1, lower panel). For RH above 97\%, the growth factor of the AerosolWater-Extract particles starts to slightly exceed even that of the first HULIS sample. This enhanced hygroscopic growth of the Aerosol-Water-Extract particles can be explained by the fact that they consist of a mixture of HULIS, low molecular weight organics and inorganic substances. The inorganic substances and low molecular weight organics may enhance the hygroscopic growth of the Aerosol-Water-Extract particles compared to the HULIS particles.

The hygroscopic growth of HULIS particles at lower RHs was investigated before. Reported growth factors lie between 1.08 and 1.47 at a RH of 90\% (Dinar et al., 2007; Gysel et al., 2004). Depending on the sample source the growth factors vary. For example, fresh HULIS from wood fires (i.e. biomass burning, where the HULIS is supposed to originate as a primary aerosol) has a growth factor of 1.18 , while the growth factor of HULIS extracted from aged wood burning particles is 1.24 and from background particles 1.47 (Dinar et al., 2007). Our growth factors at a RH of $90 \%$ for the first and second HULIS sample are 1.17 and 1.05, respectively, which agrees with the formerly reported values. Measured growth factors for Aerosol-Water-Extract at a RH of $90 \%$ vary between 1.48 and 1.52 (Gysel et al., 2004). At a RH of 
about $90 \%$, our growth factor is systematically smaller, i.e., 1.11 for the Aerosol-Water-Extract. This underlines the fact that the properties of both HULIS and Aerosol-Water-Extract may vary as function of sample location. In urban air, where our samples originated from, HULIS is thought to be formed mainly as secondary aerosol by chemical reactions followed by oligomerization and polymerization. Indeed, the watersoluble organic carbon (WSOC) for the sampling location in summer 2006 accounted for $(32 \pm 8) \%$ of the organic carbon (OC), which is substantially less than for aerosol originating from main sources other than road traffic (Salma et al., 2007). The mean WSOC/OC concentration ratios for continental background sites, and for tropical biomass burning aerosols were up to about 0.7 . Such variations in the abundance of oxygenated (and thus more water soluble) organics in samples of dissimilar origin can definitely cause differences in the hygroscopic properties of HULIS and of Aerosol-WaterExtract as well.

\subsection{Activation}

The measured critical supersaturations of water vapor needed for the activation of HULIS and Aerosol-Water-Extract particles are given as function of dry particle size in Fig. 2. Vertical error bars correspond to the standard deviation as derived from the results of three independent measurements. Horizontal error bars correspond to the step-size used for scanning dry diameters during the activation measurements. Analogous to the results of the hygroscopic growth measurements, the activation behavior of both HULIS samples is similar. At the same water vapor saturation the dry diameter of the particles that activate is significantly smaller for the Aerosol-Water-Extract particles than for the HULIS particles. At a water vapor supersaturation of about $0.4 \%$, the critical diameter for activation was found to be $37.5 \mathrm{~nm}$ for the Aerosol-Water-Extract and $92.5 \mathrm{~nm}$ for the HULIS particles. I.e., consistent with the observed hygroscopic growth, particles generated from Aerosol-Water-Extract are clearly more $\mathrm{CCN}$-active. Again, the explanation for this behavior is most likely the presence of low molecular weight organics and inorganics in the Aerosol-Water-Extract particles which enhances the CCN-activity (Asa-Awuku et al., 2008).

We also compared our results to those of two other studies examining particles consisting of HULIS extracted from atmospheric aerosol samples. In these studies, HULIS extracted from particles sampled in Israel (Dinar et al., 2006b) and the USA (Asa-Awuku et al., 2008) were considered. In both studies the HULIS particles were found to be more $\mathrm{CCN}$ active than in our investigation. At a supersaturation of roughly $1 \%$ we observed activation for particles with dry diameters of $50 \mathrm{~nm}$ (first HULIS sample) and $46 \mathrm{~nm}$ (second HULIS sample). For the same supersaturation, in the earlier studies, particles with dry diameters between $33 \mathrm{~nm}$ and $40.6 \mathrm{~nm}$ were activated. At a supersaturation of about $0.5 \%$ our first HULIS sample activated at $75 \mathrm{~nm}$ dry diameter while

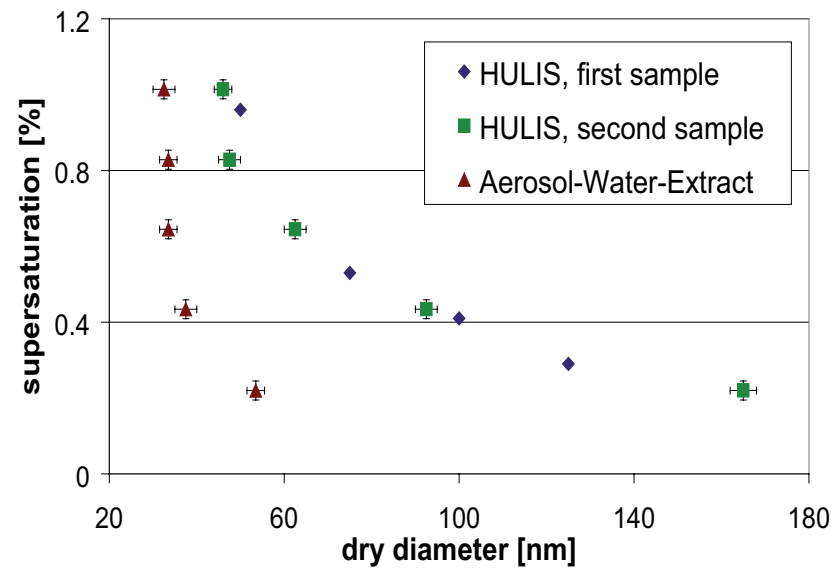

Fig. 2. Critical supersaturations needed for the activation measured with LACIS as function of dry diameters for both HULIS-samples and the Aerosol-Water-Extract.

critical diameters reported in the earlier studies are $47.5 \mathrm{~nm}$ and $69.6 \mathrm{~nm}$. At $0.2 \%$ supersaturation we found a critical diameter of $165 \mathrm{~nm}$ and the values reported earlier vary between $81 \mathrm{~nm}$ and $133 \mathrm{~nm}$. These differences are again most likely due to the different source processes and the resulting different compositions of the HULIS samples (Graber and Rudich, 2006).

In conclusion, although the HULIS samples investigated in this study show comparable hygroscopic growth and activation behavior, this is not necessarily the case for HULIS in general, since HULIS particles from different origins may vary significantly. This will also become obvious in Sect. 5.3, where we show results obtained with our parameterization tool, applied to data sets of atmospheric HULIS samples obtained by Dinar et al. (2006b) and Dinar et al. (2007). The similarity between the two HULIS samples prepared for our study are due to the fact that the actual meteorological and air quality conditions for the first and second aerosol collections were quite similar, and both sampling campaigns were realized at the same urban site, which means similar influence of emission sources.

\section{Theory}

\subsection{Background}

The hygroscopic growth of particles can be described by the Köhler theory (Köhler, 1936). The Köhler Eq. (1) combines an increase of the water vapor pressure above a curved surface with a decrease of the water vapor pressure over an aqueous solution surface. These effects are called Kelvin and Raoult effect, respectively.

$$
S=\exp \left(\frac{4 M_{w} \sigma}{R T \rho_{w} d_{p}}-\frac{v \phi n_{s}}{n_{w}}\right)
$$


Here, $S$ is the water vapor saturation over the droplet surface, $M_{w}$ the molecular weight of water, $R$ the universal gas constant, $T$ the absolute temperature, $d_{p}$ the particle diameter and $\rho_{w}$ the density of pure water. Furthermore, $\sigma$ is the surface tension of the solution, $v$ the number of ions a molecule dissociates to in solution, $\phi$ the osmotic coefficient and $n_{s}$ and $n_{w}$ the number of moles from the solute and water, respectively. The number of moles of solute can be rewritten as

$n_{s}=\frac{\pi \rho_{s} d_{p, 0}^{3}}{6 M_{s}}$

with the density and the molecular weight of the solute $\rho_{s}$ and $M_{s}$, and with the dry particle diameter $d_{p, 0}$. Thus, with Eq. (2) the Köhler Eq. (1) becomes

$S=\exp \left(\frac{4 M_{w} \sigma}{R T \rho_{w} d_{p}}-\frac{\nu \phi \rho_{s} M_{w}}{\rho_{w} M_{s}} \frac{d_{p, 0}^{3}}{d_{p}^{3}-d_{p, 0}^{3}}\right)$

Here $d_{p, 0}$ and $d_{p}$ are the diameters of the dry and the wet particle, respectively.

The unknown quantities in Eq. (3) are $\sigma, v$, and $\phi$. Also, $M_{s}$ and $\rho_{s}$ are often unknown when atmospheric particles are considered. The unknown quantities in the second term of the Köhler Eq. (3) can be summarized in a single parameter $\rho_{\text {ion, }}$, which was established by Wex et al. (2007a) and is defined as

$\rho_{\text {ion }}=\frac{\nu \phi \rho_{s}}{M_{s}}$

The surface tension can be parameterized by the Szyszkowski-Langmuir equation (Szyszkowski, 1908; Facchini et al., 1999)

$\sigma=\sigma_{\text {water }}-a T \ln (1+b C)$

were $\sigma_{\text {water }}$ is the surface tension of pure water, $a$ and $b$ are the Szyszkowski-parameters and $C$ the concentration of the solution in moles of solute per mass of water. The concentration of the solution can be substituted by

$C=\frac{\rho_{s}}{M_{s} \rho_{w}} \frac{d_{p, 0}^{3}}{d_{p}^{3}-d_{p, 0}^{3}}$

With Eq. (6), the Szyszkowski Eq. (5) can be rewritten as

$\sigma=\sigma_{\text {water }}-a T \ln \left(1+b^{\prime} \frac{d_{p, 0}^{3}}{d_{p}^{3}-d_{p, 0}^{3}}\right)$

The new parameter $b^{\prime}$ combines the "old" Szyszkowski parameter $b$ with the unknown properties of the solute and the density of water:

$b^{\prime}=b \cdot \frac{\rho_{s}}{M_{s} \rho_{w}}$

For substances like HULIS with unknown dissociation behavior, density and molecular weight, which influence the surface tension of the solution, a rearranged form of the Köhler equation can be written when applying Eqs. (7) and (4). This equation will be used in the parameterization procedure described below.

$$
\begin{aligned}
& S=\exp \\
& \left(\frac{4 M_{w}\left(\sigma_{\text {water }}-a T \ln \left(1+b^{\prime} \frac{d_{p, 0}{ }^{3}}{d_{p}^{3}-d_{p, 0} 0^{3}}\right)\right)}{R T \rho_{w} d_{p}}-\frac{\rho_{\text {ion }} M_{w}}{\rho_{w}} \frac{d_{p, 0}{ }^{3}}{d_{p}^{3}-d_{p, 0}{ }^{3}}\right)
\end{aligned}
$$

It should be noted, that possible partitioning effects (Sorjamaa et al., 2004) on both the Raoult and the Kelvin term are not treated explicitly here. However, if these effects are important they will influence the parameters $\rho_{\text {ion }}, a$ and $b^{\prime}$ implicitly.

\subsection{An iterative scheme to retrieve a parameterization}

The hygroscopic growth of aerosol particles is more influenced by the Raoult effect, i.e., the number of molecules in the solution, than by the Kelvin effect, i.e., the effect of the surface tension. In contrast, considering the activation of aerosol particles, the influence of the Kelvin term may be larger than that of the Raoult term. Taking advantage of this, we developed an iterative scheme to derive $\rho_{\text {ion }}$ and the parameters $a$ and $b^{\prime}$ of the Szyszkowski Eq. (7) from the combination of both, hygroscopic growth and activation measurements. The iterative scheme can be outlined as follows:

- determination of a first guess for $\rho_{\text {ion }}$ using a rearranged form of Eq. (9), i.e.,

$$
\begin{aligned}
\rho_{\text {ion }}= & \frac{\rho_{w}\left(d_{p}^{3}-d_{p, 0}^{3}\right)}{M_{w} d_{p, 0}^{3}} \\
& \cdot \frac{4 M_{w}\left(\sigma_{\text {water }}-a T \ln \left(1+b^{\prime} \frac{d_{p, 0}^{3}}{d_{p}^{3}-d_{p, 0}^{3}}\right)\right)}{R T \rho_{w} d_{p}} \\
& -\ln (S)
\end{aligned}
$$

assuming the surface tension $\sigma$ to be that of pure water, i.e., $72.8 \mathrm{mN} / \mathrm{m}(a=0)$ and considering only the equilibrium diameters measured with LACIS at the highest RHs (between $98.25 \%$ and $99.7 \%$ ).

- adjustment of the Szyszkowski-parameters $a$ and $b^{\prime}$ by minimizing the least square difference between the measured and the calculated (Eq. 9) critical supersaturations needed for activation.

- calculation of $\rho_{\text {ion }}$ using the Szyszkowski-parameters $a$ and $b^{\prime}$ as determined in the previous step.

- repetition of the second and third step until convergence is reached for $\rho_{\text {ion }}$ and the Szyszkowski-parameters $a$ and $b^{\prime}$. 


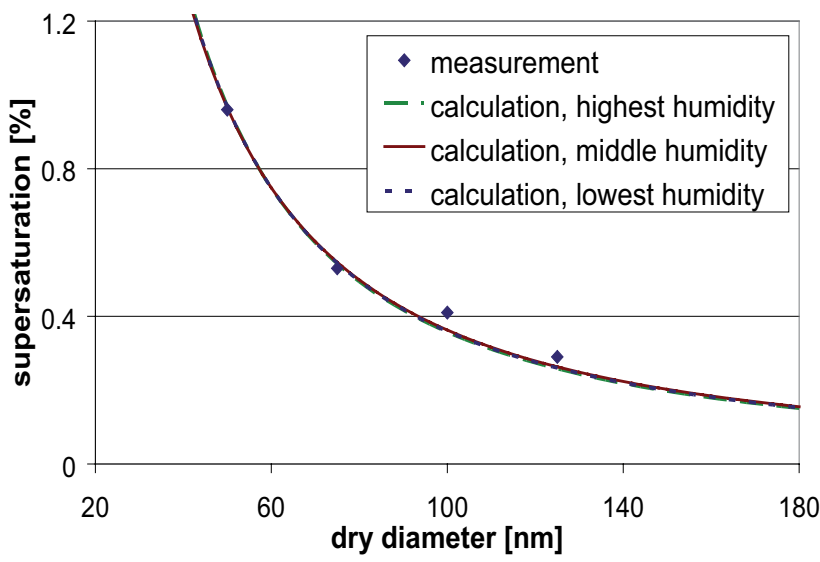

Fig. 3. Measured (symbols) and calculated (lines) critical supersaturations as function of dry particle diameter for the first HULIS sample.

The procedure yields a parameterization for hygroscopic growth and activation of aerosol particles, based on $\rho_{\text {ion }}$ and the Szyszkowski-parameters $a$ and $b^{\prime}$ being fitted to consistently describe experimental hygroscopic growth and activation data. However, the procedure relies on the assumption of a constant $\rho_{\text {ion }}$ in the high (larger than $98 \%$ ) RH range. The validity of this assumption will be discussed below.

\section{Results of parameterization}

Utilizing the experimental data and the parameterization approach described above, values for $\rho_{\text {ion }}$ and the Szyszkowskiparameters $a$ and $b^{\prime}$ were determined for the two HULIS samples and the Aerosol-Water-Extract.

\subsection{HULIS}

Figures 3 and 4 depict the results obtained regarding the parameterization of the activation behavior for the two HULIS samples investigated. Plotted are critical supersaturations as function of dry particle diameter. Given are the measured values (symbols) and the results of the parameterization (lines).

Theoretical curves for three different values of $\rho_{\text {ion }}$ (and as a consequence, three different values for the Szyszkowski parameters $a$ and $b^{\prime}$ ) are shown. These three parameter sets were determined using, in the iteration scheme, the three different growth factors (highest, middle, lowest humidity) determined experimentally with LACIS in the RH range larger than $98 \%$. Each of the three parameter sets produced comparable results for the activation behavior. This is a strong indication that the assumption of a constant $\rho_{\text {ion }}$ in the high $\mathrm{RH}$ regime is justified for the HULIS samples investigated here. In general, the agreement between the measured and

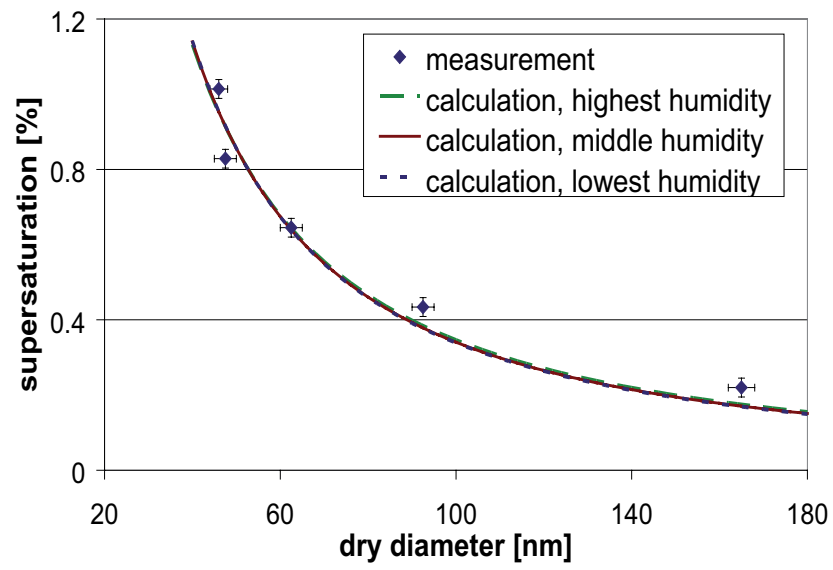

Fig. 4. Measured (symbols) and calculated (lines) critical supersaturations as function of dry particle diameter for the second HULIS sample.

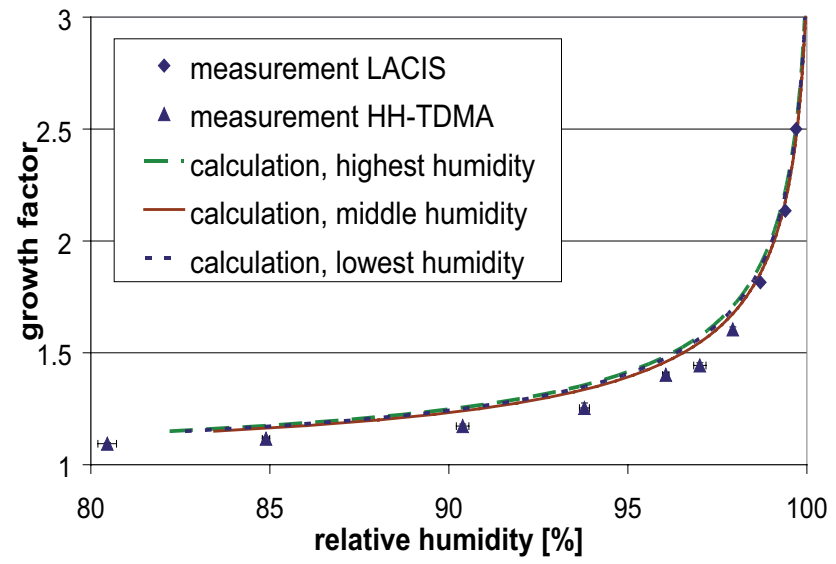

Fig. 5. Measured (symbols) and calculated (lines) growth factors as function of RH for the first HULIS sample (dry diameters: LACIS $200 \mathrm{~nm}, \mathrm{HH}-\mathrm{TDMA} 100 \mathrm{~nm}$ ).

the calculated values is very good for both samples underlining the applicability and validity of the parameterization scheme suggested here.

Figures 5 and 6 depict the corresponding results regarding the hygroscopic growth behavior of the two HULIS samples. Plotted are measured and calculated growth factors as function of RH. Here again growth factors measured with the $\mathrm{HH}-$ TDMA (triangles) are included and calculated curves (lines) for the three different parameter sets are given.

Again, the agreement between the measured and the calculated growth factors is strikingly good supporting the assumption of a constant $\rho_{\text {ion }}$ in the high RH regime. However, for RHs below $98 \%$ significant differences between the measured and calculated growth factors start to occur, especially for the second HULIS sample. These differences could 


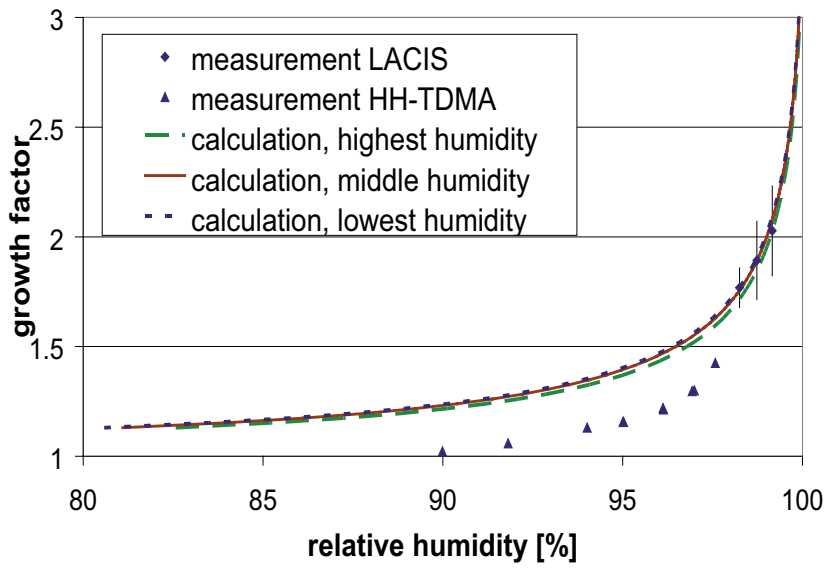

Fig. 6. Measured (symbols) and calculated (lines) growth factors as function of $\mathrm{RH}$ for the second HULIS sample (dry diameters: LACIS $230 \mathrm{~nm}$, HH-TDMA 100 and $230 \mathrm{~nm}$ ).

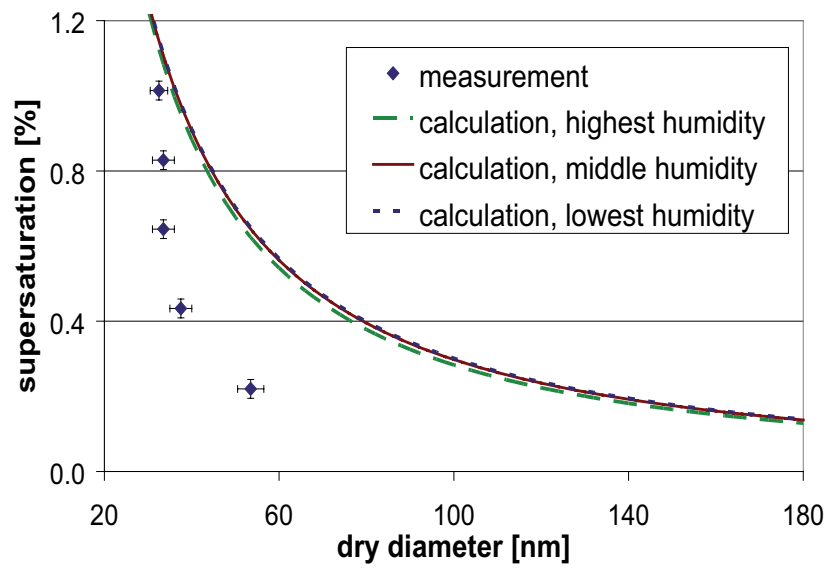

Fig. 7. Measured (symbols) and calculated (lines) critical supersaturations as function of dry particle diameter for the Aerosol-WaterExtract sample.

be explained as being a result of using two different instruments, i.e., LACIS and the HH-TDMA. However, as will be discussed below, there is evidence that this is not the case and therefore the occurring deviations might be attributed to a varying non-ideal behavior of the solution droplets resulting in e.g. a variable osmotic coefficient and consequently a variable $\rho_{\text {ion }}$ (see the definition of $\rho_{\text {ion }}$ in Eq. 4). Another effect which could cause the observed differences would be the presence of slightly soluble compounds in the HULIS samples that only dissolve above a certain RH, or, alternatively, an additional dissociation of molecules that comprise HULIS towards larger RHs, i.e. towards more diluted solutions.

Tables 1 and 2 summarize the parameters determined during the parameterization effort and the derived surface tensions at the point of activation, respectively.
Table 1. Szyszkowski-parameters and $\rho_{\text {ion }}$ for the two HULIS samples.

\begin{tabular}{cccc}
\hline Substance & $\mathrm{a}[1 / \mathrm{K}]$ & $\mathrm{b}^{\prime}$ & $\rho_{\text {ion }}\left[\mathrm{mol} / \mathrm{m}^{3}\right]$ \\
\hline HULIS, first sample & $9.505 \times 10^{-6}$ & 100 & 5434 \\
HULIS, second sample & $2.14 \times 10^{-5}$ & 100 & 5268 \\
\hline
\end{tabular}

Table 2. Calculated surface tension at the point of activation for the two HULIS samples.

\begin{tabular}{ccc}
\hline Substance & $\begin{array}{c}\text { dry diameter } \\
{[\mathrm{nm}]}\end{array}$ & $\begin{array}{c}\text { surface tension } \\
{[\mathrm{mN} / \mathrm{m}]}\end{array}$ \\
\hline HULIS, first sample & 50 & 67.8 \\
HULIS, first sample & 75 & 69.1 \\
HULIS, first sample & 100 & 69.6 \\
HULIS, first sample & 125 & 70.3 \\
HULIS, second sample & 46 & 60.9 \\
HULIS, second sample & 47.5 & 62.0 \\
HULIS, second sample & 62.5 & 63.3 \\
HULIS, second sample & 92.5 & 65.2 \\
HULIS, second sample & 165 & 67.9 \\
\hline
\end{tabular}

From the given values it can be concluded that, the differences between the two HULIS samples seem to mainly arise from differences in the surface tension and that the surface tensions at the point of activation can be significantly lower than that of water, especially for smaller dry particle diameters and consequently smaller and higher concentrated droplets. This is in agreement with the results given in Wex et al. (2007a).

\subsection{Aerosol-Water-Extract}

The parameterization approach successfully used to parameterize the two HULIS samples as outlined above was also applied to the data gained regarding the activation and the hygroscopic growth of particles generated from the AerosolWater-Extract. Figures 7 and 8 depict the results, i.e., the measured and calculated critical supersaturation as function of particle dry diameter and particle growth factors as function of $\mathrm{RH}$, respectively.

As to be seen from Fig. 7, although the iterative procedure converged, the determined values for $\rho_{\text {ion }}$ and the Szyszkowski parameters $a$ and $b^{\prime}$ are not suitable to describe the activation behavior of the Aerosol-Water-Extract. This is in line with the findings of Asa-Awuku et al. (2008) and implies that HULIS, although being present in the sample, may not be the species controlling the hygroscopic growth and activation behavior of the Aerosol-Water-Extract. 


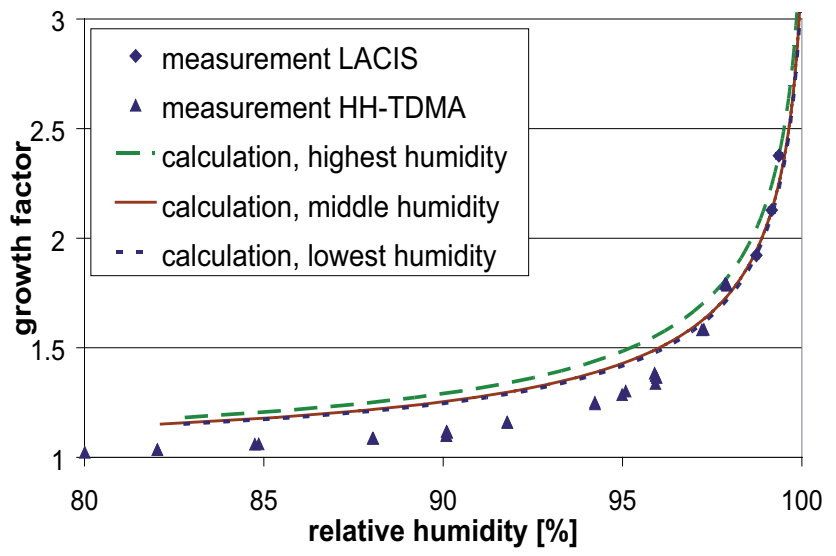

Fig. 8. Measured (symbols) and calculated (lines) growth factors as function of RH for the Aerosol-Water-Extract sample (dry diameters: LACIS $165 \mathrm{~nm}$, HH-TDMA $100 \mathrm{~nm}$ ).

Despite the fact that the activation behavior is described rather poorly, the hygroscopic growth, shown in Fig. 8, is predicted with good accuracy. This holds even down to RHs around $97 \%$ and consequently into the RH range investigated utilizing the HH-TDMA. This a) makes experimental artefacts due to the usage of two different instruments, i.e., LACIS and the HH-TDMA, unlikely and b) again suggests a variable $\rho_{\text {ion }}$ in the lower RH range.

Speculating, with respect to possible explanations for the observed behavior of the Aerosol-Water-Extract, two reasons seem possible: a) the assumption of a constant $\rho_{\text {ion }}$ may not be adequate for the Aerosol-Water-Extract investigated here, i.e., even at RHs larger than $99 \%$ non-ideal behavior may occur and/or there might still be a undissolved or slowly dissolving core inside the droplets; b) the Szyszkowski equation might not have the correct functional form to describe the surface tension-concentration relation valid for the droplets near activation. Sjogren et al. (2007) describe a slight increase of hygroscopic growth factors for particles consisting of a mixture of ammonium sulfate with humic acid sodium salt for an increasing residence time under humidified conditions at $90 \% \mathrm{RH}$, from 1.12 to 1.16 for residence times of 2 to $120 \mathrm{~s}$. This effect however is too small to explain the discrepancy in our results. This discrepancy could rather be attributed to a salting-out effect as also described by AsaAwuku et al. (2008). Salting-out might cause an enrichment of the surface active components of the Aerosol-WaterExtract (namely the HULIS fraction) at the droplet surface and might lower the surface tension excessively, to an extent that can not be captured with the Szyszkowski approach any more. Of course, also a combination of the two effects a) and $b$ ) is possible. However, this will be the topic of future investigations and could not be investigated in more detail within the scope of this paper simply because of the limited availability of the Aerosol-Water-Extract.

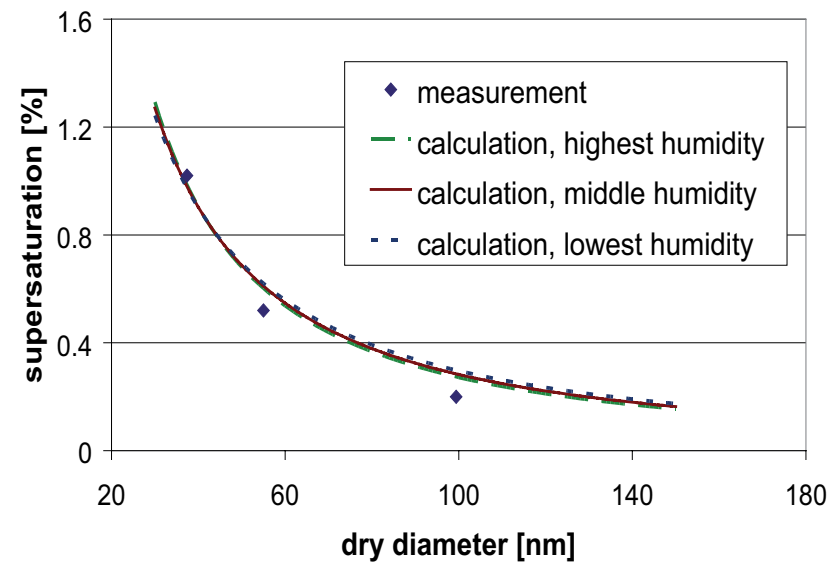

Fig. 9. Similar to Figures 3 and 4, exemplarily for the LBO-Day sample as given in by Dinar et al. (2006b) and Dinar et al. (2007).

\subsection{Applying our method to a further data set}

Dinar et al. (2006b) and Dinar et al. (2007) have investigated the hygroscopic growth and activation behavior of three different atmospheric HULIS samples. The samples were taken at the Weizmann Institute, Rehovot, Israel. A first HULIS sample was extracted from an atmospheric aerosol sample that was collected during a night in which, due to a national holiday, much wood was burned. From this fresh wood smoke aerosol, freshly formed HULIS, generated by pyrolysis, was extracted (LBO-Night). A second sample was taken at the subsequent day, representing aged HULIS (LBO-Day). The third sample was taken during summer month over the course of three weeks during daytime (3WSFA). For details for sampling and extraction see Dinar et al. (2006b). The data from this study were used to examine the applicability of the new parameterization scheme.

Figure 9 is similar to Figs. 3 and 4, showing the results obtained from the parameterization of the activation behavior of the LBO-Day sample. The measured and theoretical results regarding the hygroscopic growth from this sample are depicted in Fig. 10, which is otherwise similar to Figs. 5 and 6. The summarized parameters and surface tensions at the point of activation for all three samples examined in Dinar et al. (2006b) and Dinar et al. (2007), as determined during the parameterization, are given in Tables 3 and 4, respectively.

It can be seen that the parameterization procedure worked out in principle for these data, too, yielding values for $\rho_{i o n}$ and the surface tension in about the same range than those for our HULIS samples. An increase of $\rho_{\text {ion }}$ with increasing age of HULIS (from fresh to aged wood smoke to daytime samples) can be seen. This can be attributed to either an increase in $\rho_{s}$ of HULIS, or an increase in its degree of dissociation in solution or in its ideal behavior, or it can originate in a 
Table 3. Szyszkowski-parameters and $\rho_{\text {ion }}$ for the HULIS samples investigated by Dinar et al. (2006b) and Dinar et al. (2007).

\begin{tabular}{cccc}
\hline Substance & $\mathrm{a}[1 / \mathrm{K}]$ & $\mathrm{b}^{\prime}$ & $\rho_{\text {ion }}\left[\mathrm{mol} / \mathrm{m}^{3}\right]$ \\
\hline LBO-Night & $3.511 * 10^{-5}$ & 100 & 3516 \\
LBO-Day & $3.568 * 10^{-5}$ & 100 & 7317 \\
3WSFA & $2.678 * 10^{-5}$ & 100 & 13269 \\
\hline
\end{tabular}

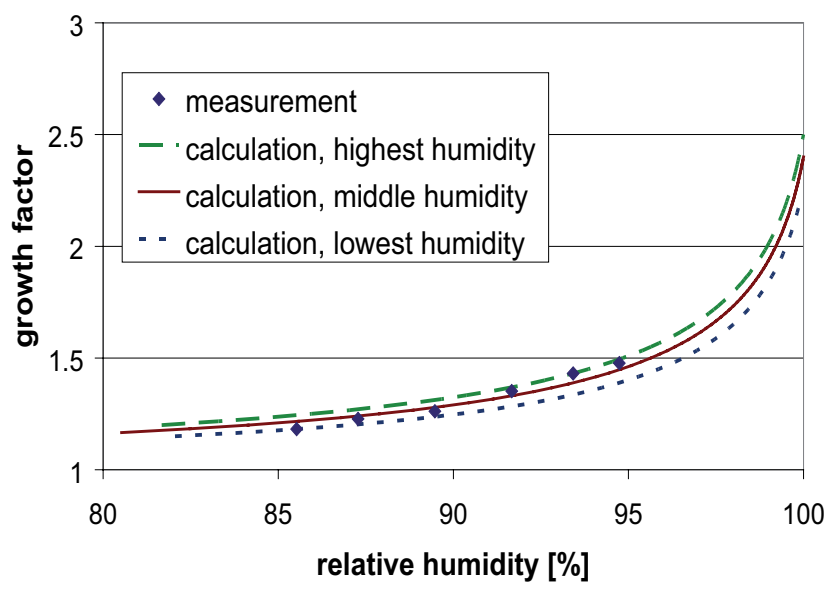

Fig. 10. Similar to Figures 5 and 6, exemplarily for the LBO-Day sample as given in Dinar et al. (2006b) and Dinar et al. (2007).

decrease of the HULIS $M_{s}$. Also, larger values of the surface tension, approaching that of water, were found for an increasing age of the atmospheric HULIS. It also should be noted, that the hygroscopic growth measurements for these samples were done only up to $95 \%$. It might be possible that the hygroscopic growth would be enhanced at larger RHs, as it was the case for our HULIS samples. This then would lead to a general shift of the derived surface tensions to larger values, closer to that of water, but there is no additional data available to test this hypothesis. We conclude by saying, that the parameterization that was developed in our paper also worked successfully for three additional atmospheric samples, the data of which we got from literature, and that an influence of aging and/or source of HULIS on the coefficients of the parameterization could be seen.

\section{Summary and conclusions}

In this study the hygroscopic growth and activation behavior of particles generated from two HULIS and one Aerosol-Water-Extract sample were investigated utilizing both, LACIS and a HH-TDMA. The samples were taken in downtown Budapest, Hungary. The first HULIS sample was collected in spring 2005. The second HULIS sample and the
Table 4. Calculated surface tension at the point of activation for the HULIS samples investigated by Dinar et al. (2006b) and Dinar et al. (2007).

\begin{tabular}{ccc}
\hline Substance & $\begin{array}{c}\text { dry diameter } \\
{[\mathrm{nm}]}\end{array}$ & $\begin{array}{c}\text { surface tension } \\
{[\mathrm{mN} / \mathrm{m}]}\end{array}$ \\
\hline LBO-Night & 40.6 & 52.1 \\
LBO-Night & 69.6 & 57.9 \\
LBO-Night & 133.8 & 64.4 \\
LBO-Day & 37.4 & 59.3 \\
LBO-Day & 55 & 63.7 \\
LBO-Day & 99.4 & 68.2 \\
3WSFA & 35.3 & 60.8 \\
3WSFA & 47.6 & 65.0 \\
3WSFA & 81 & 69.1 \\
\hline
\end{tabular}

Aerosol-Water-Extract were extracted from two fractions of one filter, which was collected in summer 2006.

The hygroscopic growth and activation behavior of both HULIS samples was found to be comparable, although they were taken at different times. Particles generated from Aerosol-Water-Extract show a slightly larger hygroscopic growth than the associated HULIS particles and are more $\mathrm{CCN}$ active compared to particles from both HULIS samples. Inorganic compounds and low molecular weight organics can be a reason for this behavior of the Aerosol-Water-Extract. Comparing our results to those available in the literature, we found that our HULIS and Aerosol-Water-Extract samples featured systematically smaller growth factors and were less $\mathrm{CCN}$ active. This underlines the fact that the properties of both HULIS and Aerosol-Water-Extract samples may vary as function of sample location, formation process, and particle aging in the atmosphere.

Based on the Köhler equation and the measured hygroscopic growth and activation behavior, an iterative scheme was developed for deriving a consistent parameterization to describe the hygroscopic growth and activation of complex aerosol particles with unknown or partly unknown material properties. The iterative procedure relies on the concepts of $\rho_{\text {ion }}$ and the Szyszkowski equation, to parameterize the Raoult- and the Kelvin-terms in the Köhler equation. When HULIS particles were considered, the procedure and the resulting parameterizations were found to work nicely with respect to the description of activation and hygroscopic growth in the high RH regime. However, for RHs below 98\%, gained results indicate concentration and particle size dependent $\rho_{\text {ion }}$, originating in a variable non-ideal behavior, a variable dissociation, or the existence of slightly soluble components in the sample.

Considering the Aerosol-Water-Extract sample, the parameterization scheme failed to predict the activation behavior. This is suggestive for a) non-ideal behavior of the Aerosol-Water-Extract particles even at RHs larger than 99\% 
and/or b) the the Szyszkowski equation not being the proper function to describe the surface tension near activation, possibly due to salting-out effects.

Probing the parameterization with data from literature (Dinar et al., 2006b and Dinar et al., 2007), covering atmospheric HULIS samples of different ages and sources, we find a dependence of the coefficients of the parameterization, namely $\rho_{i o n}$ and the concentration dependent surface tension, on the sample: values of $\rho_{i o n}$ increased from a fresh smoke to an aged smoke to an atmospheric summer daytime sample, and values for the surface tension were the lowest for the fresh smoke sample, approaching the surface tension of water for the other two samples.

Therefore, the parameterization developed in this study can be used as a valuable tool to get information on parameters of the examined substances, as e.g. the surface tension that is effective during hygroscopic growth and activation, that can not be approached otherwise.

Acknowledgements. The research was partially supported by the Hungarian Scientific Research Fund (contract K061193).

Edited by: M. Kulmala

\section{References}

Albrecht, B.: Aerosol, cloud microphysics, and fractional cloudiness, Science, 245, 1227-1230, 1989.

Asa-Awuku, A., Nenes, A., Sullivan, A., Hennigan, C., and Weber, R.: Investigation of molar volume and surfactant characteristics of water-soluble organic compounds in biomass burning aerosol, Atmos. Chem. Phys., 8, 799-812, 2008, http://www.atmos-chem-phys.net/8/799/2008/.

Bilde, M. and Svenningsson, B.: CCN activation of slightly soluble organics: The importance of small amounts of inorganic salts and particle phase, Tellus, 56(B), 128-134, 2004.

Broekhuizen, K., Kumar, P., and Abbatt, J.: Partly soluble organics as cloud condensation nuclei: Role of trace soluble and surface active species, Geophys. Res. Lett., 31, L01107, doi:10.1029/2003GL018203, 2004.

Dinar, E., Mentel, T., and Rudich, Y.: The density of humic acids and humic like substances (HULIS) from fresh and aged wood burning and pollution aerosol particles, Atmos. Chem. Phys., 6, 5213-5224, 2006a.

Dinar, E., Taranuik, I., Graber, E., Katsman, S., Moise, T., Anttila, T., Mentel, T., and Rudich, Y.: Cloud Condensation Nuclei properties of model and atmospheric HULIS, Atmos. Chem. Phys., 6, 2465-2482, 2006b.

Dinar, E., Taraniuk, I., Graber, E., Anttila, T., Mentel, T., and Rudich, Y.: Hygroscopic growth of atmospheric and model humic-like substances, J. Geophys. Res., 112, D05211, doi:10.1029/2006JD007442, 2007.

Dinar, E., Riziq, A. A., Spindler, C., Erlick, C., Kiss, G., and Rudich, Y.: The comples refractive index of atmospheric and model humic-like substances (HULIS) retrieved by a cavity ring down aerosol spectrometer (CRD-AS), Faraday Discuss., 137, 279-295, doi:10.1039/b703111d, 2008.
Facchini, M., Mircea, M., Fuzzi, S., and Charlson, R.: Cloud albedo enhancement by surface-active organic solutes in growing droplets, Nature, 401, 257-259, 1999.

Graber, E. and Rudich, Y.: Atmospheric HULIS: How humic-like are they? A comprehensive and critical review, Atmos. Chem. Phys., 6, 729-753, 2006,

http://www.atmos-chem-phys.net/6/729/2006/.

Gysel, M., Weingartner, E., Nyeki, S., Paulsen, D., Baltensperger, U., Galambos, I., and Kiss, G.: Hygroscopic properties of water-soluble matter and humic-like organics in atmospheric fine aerosol, Atmos. Chem. Phys., 4, 35-50, 2004, http://www.atmos-chem-phys.net/4/35/2004/.

Hennig, T., Massling, A., Brechtel, F., and Wiedensohler, A.: A tandem DMA for highly temperature-stabilized hygroscopic particle growth measurements between $90 \%$ ans $98 \%$ relative humidity, J. Aerosol Sci., 36, 1210-1223, 2005.

Henning, S., Rosenorn, T., D’Anna, B., Gola, A., Svenningsson, B., and Bilde, M.: Cloud droplet activation and surface tension of mixtures of slightly soluble organics and inorganic salt, Atmos. Chem. Phys., 5, 575-582, 2005,

http://www.atmos-chem-phys.net/5/575/2005/.

Hoffer, A., Gelencser, A., Guyon, P., Kiss, G., Schnid, O., Frank, G., Artaxo, P., and Andreae, M.: Optical properties of humic-like substances (HULIS) in biomass-burning aerosols, Atmos. Chem. Phys., 6, 3563-3570, 2006,

http://www.atmos-chem-phys.net/6/3563/2006/.

Kanakidou, M., Seinfeld, J. H., Pandis, S. N., Barnes, I., Dentener, F. J., Facchini, M. C., van Dingenen, R., Ervens, B., Nenes, A., Nielsen, C. J., Swietlicki, E., Putaud, J. P., Balkanski, Y., Fuzzi, S., Horth, J., Moortgat, G. K., Winterhalter, R., Myhre, C. E. L., Tsigaridis, K., Vignati, E., Stephanou, E. G, and Wilson, J.: Organic aerosol and global climate modelling: A review, Atmos. Chem. Phys., 5, 1053-1123, 2005,

http://www.atmos-chem-phys.net/5/1053/2005/.

Kiselev, A., Wex, H., Stratmann, F., Nadeev, A., and Karpushenko, D.: White-light optical particle spectrometer for in-situ measurements of condensational growth of aerosol particles, Appl. Optics, 44, 4693-4701, 2005.

Kiss, G., Tombacz, E., and Hansson, H.-C.: Surface tension effects of humic-like substances in the aqueous extract of tropospheric fine aerosol, J. Atmos. Chem., 50, 279-294, 2005.

Köhler, H.: The nucleus in and the growth of hygroscopic droplets, T. Faraday Soc., 32, 1152-1161, 1936.

Lance, S., Medina, J., Smith, J., and Nenes, A.: Mapping the operation of the DMT continuous Flow CCN counter, Aerosol Sci. Technol., 40, 242-254, 2006.

McFiggans, G., Artaxo, P., Baltensperger, U., Coe, H., Facchini, M. C., Feingold, G., Fuzzi, S., Gysel, M., Laaksonen, A., Lohmann, U., Mentel, T. F., Murphy, D. M., O’Dowd, C. D., Snider, J. R., and Weingartner, E.: The effect of physical and chemical aerosol properties on warm cloud droplet activation, Atmos. Chem. Phys., 6, 2593-2649, 2006,

http://www.atmos-chem-phys.net/6/2593/2006/.

Rader, D. and McMurry, P.: Application of the tandem differential mobility analyser to studies of droplet growth or evaporation, J. Aerosol Sci., 17, 771-787, 1986.

Salma, I., Ocskay, R., Varga, I., and Maenhaut, W.: Surface tension of atmospheric humic-like substances in connection with relaxation, dilution, and solution pH, J. Geophys. Res., 111, D23205, 
doi:10.1029/2005JD007015, 2006.

Salma, I., Ocskay, R., Chi, X., and Maenhaut, W.: Sampling artefacts, concentration and chemical composition of fine watersoluble organic carbon and humic-like substances in a continental urban atmospheric environment, Atmos. Environ., 41, 41064118, 2007.

Samburova, V., Zenobi, R., and Kalberer, M.: Characterisation of high molecular weight compounds in urban atmospheric particles, Atmos. Chem. Phys., 5, 2163-2170, 2005, http://www.atmos-chem-phys.net/5/2163/2005/.

Sjogren, S., Gysel, M., Weingartner, E., Baltensperger, U., Cubison, M. J., Coe, H., Zardini, A. A., Marcolli, C., Krieger,U. K. and Peter, T.: Hygroscopic growth and water uptake kinetics of two-phase aerosol particles consisting of ammonium sulfate, adipic acid and humic acid mixtures, J. Aerosol Sci., 38, 157171, 2007.

Sorjamaa, R., Svenningsson, B., Raatikainen, T., Henning, S., Bilde, M., and Laaksonen, A.: The role of surfactants in Köhler theory reconsidered, Atmos. Chem. Phys., 4, 2107-2117, 2004, http://www.atmos-chem-phys.net/4/2107/2004/.

Stratmann, F., Kiselev, A., Wurzler, S., Wendisch, M., Heintzenberg, J., Charlson, R., Diehl, K., Wex, H., and Schmidt, S.: Laboratory studies and numerical simulations of cloud droplet formation under realistic supersaturation conditions, J. Atmos. Ocean. Tech., 21, 876-887, 2004.

Szyszkowski, B.: Experimentelle Studien über kapillare Eigenschaften der wässrigen Lösungen von Fettsäuren, Z. Phys. Chem., 64, 385-414, 1908.

Tang, I.: Chemical and size effects of hygroscopic aerosols in light scattering coefficients, J. Geophys. Res., 101, 19245-19250, 1996.
Tang, I. and Munkelwitz, H.: Water activities, densities, and refractive indices of aqueous sulfate and sodium nitrate droplets of atmospheric importance, J. Geophys. Res., 99, 18 801-18 808, 1994.

Taraniuk, I., Graber, E. R., Kostinski, A., and Rudich, Y.: Surfactant properties of atmospheric and model humiclike substances (HULIS), Geophys. Res. Lett., 34, L16807, doi:10.1029/2007GL029576, 2007.

Twomey, S.: Pollution and the planetary albedo, Atmos. Environ., 8, 1251-1256, 1974.

Varga, B., Kiss, G., Ganszky, I., Gelencser, A., and Krivacsy, Z.: Isolation of water-soluble organic matter from atmospheric aerosol, Talanta, 55, 561-572, 2001.

Wex, H., Kiselev, A., Stratmann, F., Zoboki, J., and Brechtel, F.: Measured and modeled equilibrium sizes of $\mathrm{NaCl}$ and $\left(\mathrm{NH}_{4}\right)_{2} \mathrm{SO}_{4}$ particles at relative humidities up to $99.1 \%$, J. Geophys. Res., 110, D21212, doi:10.1029/2004JD005507, 2005.

Wex, H., Kiselev, A., Ziese, M., and Stratmann, F.: Calibration of LACIS as a CCN detector and its use in measuring activation and hygroscopic growth of atmospheric aerosol particles, Atmos. Chem. Phys., 6, 4519-4527, 2006, http://www.atmos-chem-phys.net/6/4519/2006/.

Wex, H., Hennig, T., Salma, I., Ocskay, R., Kiselev, A., Henning, S., Massling, A., Wiedensohler, A., and Stratmann, F.: hygroscopic growth and measured and modeled critical supersaturations of an atmospheric HULIS sample, Geophys. Res. Lett., 34, L02818, doi:10.1029/2006GL028260, 2007a.

Wex, H., Ziese, M., Kiselev, A., Henning, S., and Stratmann, F.: Deliquescence and hygroscopic growth of succinic acid particles measured with LACIS, Geophys. Res. Lett., L17810, doi:10.1029/2007GL030185, 2007b. 